\title{
Percepções e Comportamentos de Cuidado Neonatal de Mulheres Participantes de um Programa Mãe-Canguru
}

\author{
Manuela Beltrão Oliveira e Silva \\ Regina Célia Souza Brito \\ Universidade Federal do Pará
}

\begin{abstract}
RESUMO
O objetivo deste estudo foi analisar as percepções, experiências e comportamentos de cuidado neonatal de mulheres participantes de um Programa Mãe-Canguru, visando compreender como elas percebem e vivenciam a experiência. Participaram do estudo 5 díades. A idade das mães variou entre 16 e 33 anos. Foram utilizados o Inventário de Depressão de Beck e o Questionário de Aceitação Materna em relação ao Programa Mãe-Canguru. O comportamento não verbal das participantes foi registrado através de sessões diárias de observação e foram realizadas entrevistas temáticas sobre vida afetiva e família de origem, que esclareceram muitos aspectos dos dados coletados. Os resultados sugeriram que o método é bem tolerado, mas que acontecimentos externos exercem influência no comportamento e no estado emocional das participantes. As mães desempenharam as atividades prescritas e o tempo de permanência no programa parece ter sido utilizado como um momento de reflexão sobre suas vidas. Este tipo de investigação ainda precisa ser explorado em novos estudos, a fim de propiciar um desenvolvimento do Programa Mãe-Canguru.
\end{abstract}

Palavras-chave: Programa Mãe-Canguru; comportamento materno; mulher.

\begin{abstract}
Perceptions and Neonatal Care Behavior of Women in a Kangaroo-Mother Care Program

The goal of this study was to analyze the perceptions, experiences and neonatal care behavior of women in a Kangaroo-Mother Care Program so as to understand how they perceived this experience. The sample was composed of 5 mother-baby dyads (mother's ages ranged between 16 and 33 years). Collected data included the Beck Depression Inventory and the Maternal Acceptance questionnaire with respect to the Kangaroo Program. Non-verbal behavior was observed through daily sessions while two thematic interviews were used to clarify various obscure aspects of the data. The results suggest that the Kangaroo mother care Program was well tolerated by mothers, but outside factors also influenced maternal behavior and participant's emotions. All mothers followed the prescribed activities and the period spent on the Program seems to have been used as a reflective moment in their lives. Further investigations remain to be conducted, in order to improve Kangaroo-Mother Care Program development.
\end{abstract}

Keywords: Kangaroo-Mother Care Program; maternal behavior; women.

A utilização do Método Mãe-Canguru (MMC) em maternidades relata superioridade do mesmo em vários aspectos quando comparado à utilização do método tradicional (incubadora). A literatura sobre o assunto tem enfocado as necessidades do bebê e as vantagens do MMC em relação ao mesmo (Cattaneo, Davanzo, Uxa \& Tamburlini, 1998b; Charpak, Ruiz-Peláez, Figueroa \& Charpak, 1997; Kambarami, Chidede \& Pereira, 2003; Lundigton-Hoe, Nhuha \& Swinth, 2000; Miltersteiner, Miltersteiner, Rech \& Mole,
2003). No entanto, pouco se têm investigado sobre as percepções, sentimentos e vantagens do MMC, no que diz respeito à mulher/mãe, pois esta deverá permanecer internada por dias ou meses junto do bebê. Encontraram-se referências sobre o assunto em Moura (2003), que enfocou as percepções da maternidade das participantes de um programa em São Paulo; em Cattaneo e cols. (1998a) e Gadelha, Medeiros Filho, Mendes, Saad e Barbosa (2002), que utilizaram um questionário de aceitação materna em relação ao MMC. 
Nesta pesquisa objetivou-se investigar as percepções, experiências e comportamentos de cuidado neonatal de mulheres participantes de um Programa MãeCanguru, visando compreender como elas percebem e vivenciam esta experiência. Para tanto, foi necessário observar e registrar os comportamentos de cuidado neonatal apresentados pelas mães das díades participantes, registrar as descrições verbais das suas experiências e percepções, analisá-las e compará-las aos eventos comportamentais gerais e os de cuidado neonatal observados e, por fim, comparar os resultados obtidos no início e no final da participação no programa através da aplicação do Inventário de Depressão de Beck (Gorestein \& Andrade, 1998) e do Questionário de Aceitação Materna (Cattaneo e cols., 1998a) em relação ao Mãe-Canguru.

\section{A maternidade}

Uma das experiências mais difíceis na vida da mulher urbana contemporânea é sincronizar uma fase propícia da vida para exercer a maternidade. A existência de uma carreira, na vida de uma mulher moderna, que requer tempo integral, acaba se sobrepondo ao "instinto maternal".

Por milhares de anos a maternidade foi vista como um destino ao qual as mulheres estariam atadas, naturalmente, através de seus instintos e que as levariam a desejar e a cuidar de todos os filhos que parissem (Hrdy, 2001). Mas o que se entende por maternidade? Segundo Hrdy (2001), de um ponto de vista biológico, define-se a maternidade como um "processo de conceber e dar à luz" (p. 30). Já no que tange à seleção natural a maternidade é entendida como "toda e qualquer coisa que uma fêmea faz para garantir a sua representação genética em gerações subsequentes". (Hrdy, 2001, p. 99). Para Ades (2001), do ponto de vista evolutivo, o cuidado e dedicação da mãe para com os filhos seria um investimento, uma vez que o cuidado materno empregado garantirá a sobrevivência da prole até a independência. É provável, que este seja um ato inconsciente da mãe. Porém, ao se empenhar em criar um filho, almejando que ele cresça saudável e se reproduza, a mulher traduz para uma linguagem social os fatos ligados à perpetuação de seus genes, e, consequentemente, à manutenção da espécie.

Hrdy (2001), discutindo o conceito de "instinto maternal", afirmou que no Ocidente esta ideia ainda é predominante, uma vez que, por muito tempo, pensou-se que o desejo sexual da mulher só existia devido à procriação. Desta forma, a maternidade seria parte da natureza feminina e não estaria ligada à sua sexualidade, nem aos seus desejos e aspirações. Visto deste prisma o "instinto maternal" faria sentido, pois para cumprir seu papel evolutivo a mulher teria como função biológica, parir, amamentar e cuidar incondicionalmente dos filhos.

Entretanto, é interessante considerar que ter um bebê não é garantia de que a mãe dele cuidará. Uma mulher que esteja predisposta a assumir o papel de mãe tem capacidade de apegar-se a todo e qualquer bebê. Em contrapartida, uma mãe sem esta predisposição pode não se apegar ao seu próprio bebê (Hrdy, 2001).

Para as fêmeas primatas, de uma maneira geral, qualquer bebê assume forma atraente. Para elas o necessário para desencadear o amor é a proximidade física ao longo do tempo (Hrdy, 2001; Ribas \& Seidl de Moura, 2004). Tokumaru (2001) propôs a existência de uma prontidão biológica para o cuidado parental. A preparação da mulher para gerar e amamentar seu bebê se dá através da fisiologia, da anatomia e de circuitos neurais. No entanto, são as circunstâncias sociais que indicam o modo como ela irá cuidar da prole. Estas circunstâncias podem ser representadas pelas influências culturais, pela interação com o ambiente e pelo equilíbrio entre suas ambições e as exigências impostas pela maternidade.

No mundo atual, o caminho trilhado por uma nova mulher, marcado por uma maior liberdade e educação tem modificado a visão de maternidade. $O$ controle da reprodução proporcionou às mulheres o poder de escolher entre quantidade e qualidade, optando por menos filhos e aumentando o espaço entre eles (Fisher, 1995; Hrdy, 2001). Para muitas mulheres, atualmente, a realização profissional vem em primeiro lugar, e por isso renunciam ou retardam a maternidade para se dedicar à carreira (Hrdy, 2001). Mesmo assim, a maternidade continua sendo vista como um elemento muito forte da cultura e da identidade femininas pela sua associação com o corpo e a natureza.

\section{O Método Mãe-Canguru}

O bebê da espécie humana é extremamente frágil ao nascer, mesmo quando a mulher tem uma gravidez a termo, este, necessita de cuidados intensivos. Quando um bebê nasce antes de concluir os nove meses de gestação e, portanto é prematuro, há a necessidade de cuidado redobrado. Na percepção médica, o nascimento de um bebê antes do tempo, configura um grave acontecimento, pois um alto nível de óbitos está relacionado ao nascimento prematuro (Brasil, 1998; Moura, 2003). Entretanto, os avanços da medicina têm permitido o desenvolvimento de técnicas específicas 
de cuidados ao bebê prematuro e de baixo peso, aumentando a probabilidade de sobrevivência dos mesmos (Xavier, 2000). Apesar dos benefícios advindos destas novas tecnologias, ressaltam-se alguns fatores negativos como: longo tempo de internação, afastamento da díade mãe/bebê, dificuldades na manutenção do aleitamento materno, na formação do vínculo mãe/bebê e cuidados especializados de alto custo. (Xavier, 2000).

A escassez de recursos e equipamentos apropriados aliados a grande demanda de prematuros levou, em 1978, o médico Edgar Rey Sanabria, a desenvolver em Bogotá, na Colômbia o Método Mãe-Canguru MMC (Tessier e cols., 1998). Mas foi em 1979 que o neonatologista Héctor Martinez Gómez aprimorou a ideia original e a difundiu. Desde então, muitos países, inclusive países desenvolvidos, introduziram o MMC em suas enfermarias neonatais, considerando que este tipo de cuidado promoveria uma estabilidade fisiológica e acentuaria a relação pais/criança (Tessier e cols., 1998). Assim, o MMC passou a ser visto como uma metodologia alternativa em comparação a dispendiosos métodos tradicionais de cuidados ao recém nascido prematuro e de baixo peso. (Charpak e cols., 1997).

A premissa do MMC é contato pele a pele entre mãe e bebê 24 horas ao dia, onde este recebe o estímulo e o calor necessário para a estabilização de suas funções corporais e amamentação com o leite materno (Carvalho, 2001; Cattaneo e cols., 1998b). Tal cuidado assemelha-se ao cuidado desempenhado pelas ancestrais humanas, durante a Evolução, que carregavam seus filhos amarrados ao seio, permitindo que estes se alimentassem e recebessem o calor de seu corpo. Para a implementação do MMC faz-se necessária a disponibilidade da mãe em participar do programa, já que esta deve permanecer 24 horas por dia em alojamento conjunto com o bebê (Cattaneo e cols., 1998b). A adoção do Método deve ser decidida pela mãe, familiares e equipe do hospital que deverá fornecer todas as informações.

O MMC faz parte de uma política pública denominada Atenção Humanizada ao Recém-Nascido de Baixo Peso (Método Canguru) cujo objetivo é disseminar e implantar o Método, principalmente, em hospitais e maternidades vinculados ao Sistema Único de Saúde - SUS (Carvalho, 2001). No Pará, o Método Canguru foi instituído em março de 1998, na Santa Casa de Misericórdia.

Frente a todas as mudanças ocorridas sobre a visão de maternidade e o papel da mulher é que nesta pesquisa visou-se investigar a situação da mulher/mãe participante do Programa Mãe-Canguru, uma vez que pouco se tem estudado a este respeito e visto que as mães precisam abdicar de certas atividades para cuidar do bebê.

\section{MATERIAL E MÉTODO}

\section{Instrumentos}

Os instrumentos utilizados nesta pesquisa foram:

- Inventário de Depressão de Beck - I.D.B.

(Gorestein \& Andrade, 1998)

Um dos instrumentos utilizados foi a Escala de Depressão de Beck - IDB que é uma das escalas mais utilizadas em pesquisas clínicas na área (Calil e Pires, 1998; Gorestein, 1998).

- Questionário de Aceitação Materna em relação ao MMC - QAM (Cattaneo e cols., 1998a)

Este questionário teve como finalidade avaliar a aceitação e percepção materna em relação ao Programa Mãe-Canguru. Ele é composto de doze perguntas, e é uma adaptação do protocolo utilizado em um estudo com o MMC (Cattaneo e cols., 1998a), realizado em países em desenvolvimento (em Addis Abeba, na Etiópia, em Yogykarta, na Indonésia e em Mérida, no México) (Apêndice A).

\section{Participantes}

Participaram da pesquisa cinco díades mãe-bebê integrantes do Programa Mãe-Canguru da Santa Casa de Misericórdia de Belém, no Pará. Este hospital foi escolhido, por ser o único no município e no Estado a desenvolver o Método Mãe-Canguru. Os critérios de participação na pesquisa foram: ser o primeiro dia da díade no alojamento e o peso do bebê ser maior que $1.000 \mathrm{~g}$ e menor que $1.550 \mathrm{~g}$. O critério de peso do bebê foi observado por aumentar a probabilidade de permanência da díade no programa. As díades convidadas e que aceitaram participar da pesquisa, não apresentaram qualquer restrição ao preenchimento dos questionários e gravação das entrevistas. A idade das mães participantes variou de 16 a 33 anos.

\section{Procedimento}

O procedimento foi dividido em quatro fases, descritas a seguir.

Inicialmente realizou-se um levantamento de dados nos arquivos da Santa Casa recolhendo informações sobre o perfil da população atendida. Em seguida realizaram-se visitas regulares ao alojamento MMC com o objetivo de observar e conhecer a rotina do progra- 
ma. Nestas visitas foram realizadas 20 horas de observação e registro cursivo de todos os comportamentos não verbais das mães alojadas. Posteriormente estes registros foram categorizados e compuseram o catálogo comportamental utilizado nos registros posteriores.

Fase 1: Contatos pessoais e individuais foram realizados com a mãe participante da díade previamente selecionada, com o objetivo de convidá-la a participar da pesquisa e assinatura do termo de consentimento assistido para a pesquisa. A seguir foi aplicado o Inventário de Depressão de Beck - IDB (Gorestein \& Andrade, 1998), cuja finalidade foi a de levantar possíveis sintomas depressivos na mãe. Sua aplicação ocorreu no dia em que a participante iniciou sua internação no alojamento. Após o preenchimento do IDB foi aplicado o Questionário de Aceitação Materna em relação ao MMC (QAM) (Cattaneo e cols., 1998a) objetivando-se detectar o grau de aceitação e percepção do MMC do ponto de vista das participantes.

Fase 2: A partir do segundo dia de permanência da mãe realizou-se os registros das categorias comportamentais (previamente definidas), diariamente, no horário de $14 \mathrm{~h}$ as $16 \mathrm{hs}$, durante dez dias. Utilizou-se o método focal com registros ao final de cada 60 segundos. Assim cada sessão de observação com duas horas de duração era composta por 120 registros. As díades que permaneceram menos de dez dias no alojamento foram descartadas da pesquisa.

Fase 3: Ainda no segundo dia, após a admissão da díade, foram realizadas entrevistas para o levantamento da história da vida conjugal/afetiva e da família de origem (Queiroz, 1997) das participantes. Foram realizadas duas sessões de entrevistas não estruturadas, individuais, com duração aproximada de $30 \mathrm{mi}-$ nutos cada. As entrevistas foram conduzidas por temas. Entrevista 1: Eventos significativos relacionados à vida afetiva/conjugal; Entrevista 2: Eventos significativos relacionados à relação familiar com a família de origem. Cada entrevista teve início com a pesquisadora solicitando à participante que destacasse um evento significativo em sua vida, relacionado ao tema da entrevista.

Fase 4: Esta fase coincidiu com o décimo dia de permanência na enfermaria ou a alta da díade do MMC, neste momento as participantes responderam pela segunda vez o IDB (Gorestein \& Andrade, 1998; Calil \& Pires, 1998), e o QAM (Cattaneo e cols., 1998a) em relação ao MMC. O objetivo deste procedimento foi comparar os resultados obtidos na primeira e na segunda aplicação.
Após a coleta dos dados com a primeira díade iniciou-se a abordagem e coleta com a segunda díade e assim sucessivamente.

\section{ANÁLISE DOS DADOS}

Os dados nas fases 1 e 4 através da aplicação do IDB (Gorestein \& Andrade, 1998) e QAM (Cattaneo e cols., 1998a) foram analisados, quantificados e apresentados em tabelas, comparando os índices obtidos na primeira e segunda aplicações.

A análise das entrevistas iniciou com as transcrições do conteúdo das mesmas, registrando as falas em sentido literal, que em seguida foram cuidadosamente lidas e comparadas ao material da fita, para garantir fidedignidade e conhecimento do conteúdo. Após esta etapa procedeu-se à análise de conteúdo, onde se realizou uma análise categorial das falas, optando-se por categorias de registro estabelecidas a posteriori e de contexto estabelecidas a priori. As categorias de registro foram estabelecidas após a leitura do material, tendo por unidade de análise trechos das falas das participantes, que determinassem algum comportamento. Já as de contexto levaram em consideração os temas das entrevistas de história de vida, o local onde as mães estavam internadas e o lazer.

Optou-se por analisar os dados obtidos a partir das observações dos comportamentos não verbais apenas do terceiro ao sétimo dia (cinco dias) de observações, descartando-se os dois primeiros e os dois últimos dias para que houvesse menor efeito das variáveis de adaptação ao programa.

Os dados comportamentais foram analisados, as frequências foram quantificadas e transformadas em frequências relativas, contabilizando assim os comportamentos desempenhados. As entrevistas realizadas buscaram conhecer aspectos da história de vida das participantes em relação a sua vida afetiva e da família de origem, objetivando estabelecer relações mais sólidas entre os diferentes dados registrados.

\section{RESULTADOS}

Os resultados apresentados, a seguir, referem-se às cinco díades mãe-bebê (P1 a P5) compostas por mulheres entre 16 e 33 anos, três delas viviam com o companheiro, uma era casada e uma solteira. Quanto ao número de filhos duas já eram mães, as outras três eram primíparas. Em relação à escolaridade, duas declararam possuir o ensino fundamental completo, duas o ensino médio completo e uma o ensino funda- 
mental incompleto. Sobre as atividades profissionais três declararam trabalhar fora e duas eram donas de casa. Três participantes eram provenientes da capital (Belém), e duas do interior do Estado.

O tempo de permanência das díades no Programa Mãe-Canguru variou entre 10 a 30 dias, a idade gestacional ao nascimento foi de sete meses (P1, P2, P3 e
P5) e oito meses (P4); e o peso dos bebês ao nascer variou de $900 \mathrm{~g}$ a $1.350 \mathrm{~g}$. O peso médio dos bebês ao entrarem no programa foi de $1.335 \mathrm{~g}$ e a média de dias de permanência da díade na enfermaria canguru foi 18,6 dias, dependendo de fatores relativos ao estado de saúde e prematuridade do bebê.

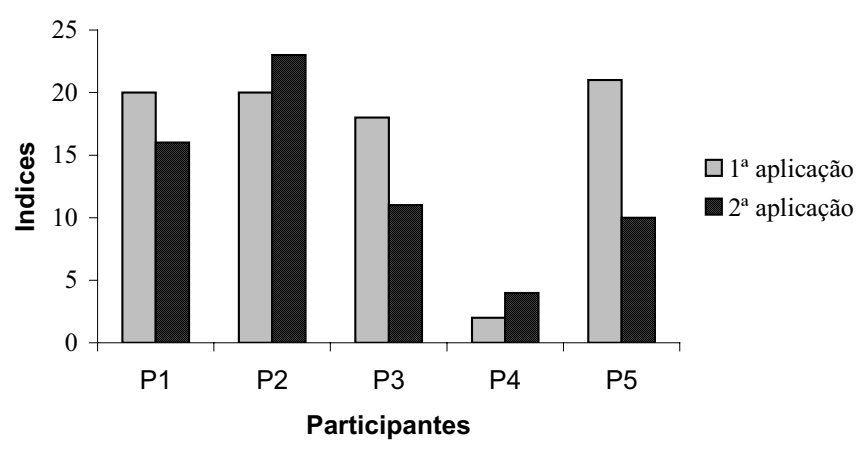

Figura 1. Índices obtidos por participante no Inventário de Depressão de Beck na primeira e na segunda aplicação.

Na Figura 1 apresentam-se os resultados da aplicação do Inventário de depressão de Beck - IDB (Gorestein \& Andrade, 1998). Os pontos de corte utilizados nesta pesquisa foram os seguintes (índices de corte sem diagnóstico prévio): menor que 15 , sem depressão; maior que 15 , disforia e acima de 20 "depressão" (Gorestein \& Andrade, 1998).

$\mathrm{Na}$ primeira aplicação do IDB (Gorestein \& Andrade, 1998) predominaram índices elevados, os quais podem indicar possíveis sintomas de depressão, com exceção de uma participante que apresentou baixo índice. O índice mais alto apresentado foi 21 e o menor, 02. Na segunda aplicação predominou uma redução dos índices, com exceção de duas participantes que tiveram seus índices aumentados para 23 e 04 respectivamente, sendo que o aumento do índice de uma delas não configurou depressão. $\mathrm{Na}$ segunda aplicação o maior índice registrado foi 23 (P2) e o menor foi 04

No Questionário de Aceitação Materna - QAM (Cattaneo e cols., 1998a) utilizou-se o mesmo critério de aplicação do IDB (Gorestein \& Andrade, 1998). Para uma melhor visualização dos resultados obtidos agrupamos as perguntas em tabelas distintas, conforme o enfoque das mesmas.

TABELA 1

Respostas Obtidas no QAM em Relação ao Mãe-Canguru

\begin{tabular}{|c|c|c|c|c|c|c|}
\hline \multirow[b]{3}{*}{ Perguntas } & \multicolumn{6}{|c|}{ Respostas } \\
\hline & \multicolumn{2}{|c|}{ SIM } & \multicolumn{2}{|c|}{ NÃO } & \multicolumn{2}{|c|}{ ÀS VEZES } \\
\hline & $1^{a} \mathrm{APL}$ & $2^{a} \mathrm{APL}$ & $1^{a} \mathrm{APL}$ & $2^{a} \mathrm{APL}$ & $1^{a} \mathrm{APL}$ & $2^{\mathrm{a}} \mathrm{APL}$ \\
\hline Satisfeita com a prescrição do método ? & 5 & 5 & & & & \\
\hline Preferia o outro ? (Tradicional) & & & 5 & 5 & & \\
\hline Acha o método fácil ? & 5 & 5 & & & & \\
\hline Acha o método conveniente? & 5 & 5 & & & & \\
\hline Ajuda os outros ? & 1 & 3 & 3 & 1 & 1 & 1 \\
\hline Sente-se preocupada com o bebê ? & 3 & 5 & 1 & & 1 & \\
\hline Sente-se capaz de cuidar do bebê em casa? & 4 & 4 & 1 & 1 & & \\
\hline Sente-se confortável ? & 5 & 3 & - & 1 & - & 1 \\
\hline Sente-se preocupada consigo? & 3 & 3 & 2 & 2 & & \\
\hline O pai concorda? & 4 & 5 & - & - & 1 & \\
\hline A família concorda? & 4 & 5 & - & - & 1 & \\
\hline
\end{tabular}


TABELA 2

Respostas à Questão "O Que Mais Lhe Preocupa?" no QAM

\begin{tabular}{cll}
\hline $\begin{array}{c}\text { O que mais lhe } \\
\text { preocupa? }\end{array}$ & \multicolumn{1}{c}{$1^{\text {a } \text { aplicação }}$} & \multicolumn{1}{c}{$2^{\text {a }}$ aplicação } \\
\hline P1 & Só o que me preocupa são meus filhos & Os filhos que estão em casa \\
P2 & Não & O peso do bebê \\
P3 & Quando sair do hospital a situação financeira & Sim, a situação financeira \\
P4 & Saúde e bem estar do bebê & A saúde do bebê \\
P5 & Querer ir para casa, pois não gosta de estar & Ganho de peso do bebê para sair do hospital \\
& hospedada na casa da sogra & \\
\hline
\end{tabular}

A Tabela 1 demonstrou que todas as participantes, em ambas as aplicações, afirmaram estar satisfeitas com a prescrição do Método, todas afirmaram preferir o MMC ao método tradicional (incubadora). Afirmaram também que achavam o Método fácil. Quanto à conveniência do Método todas as respostas foram afirmativas nas duas aplicações. No quesito preocupação com o bebê, obteve-se oito afirmativas entre a primeira e a segunda aplicação do QAM, e apenas uma mãe declarou não estar preocupada com o bebê. No item relacionado à capacidade de cuidar do bebê em casa, apenas uma participante respondeu não se sentir capaz.

A pergunta relacionada a sentir-se confortável registrou predominância de respostas afirmativas, tendose encontrado apenas uma resposta negativa. No quesito Preocupa-se Consigo Mesma, três afirmaram preocupações pessoais e duas negaram ter este tipo de preocupação. Sobre a concordância dos familiares (marido e família de origem) com a participação da díade no programa, a tendência foi uma afirmativa positiva nas duas aplicações.

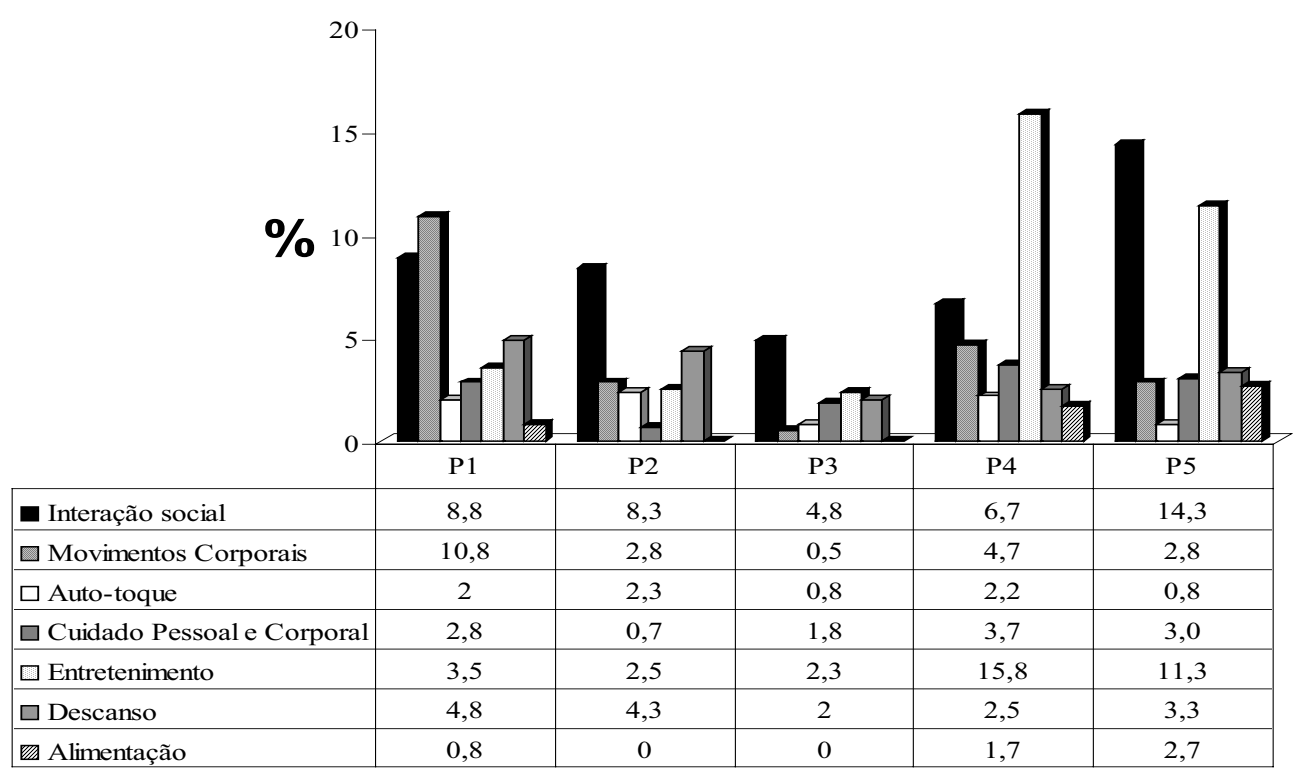

Figura 2. Frequências relativas dos resultados das observações das mães (cinco dias) referentes aos comportamentos voltados para si.

$\mathrm{Na}$ figura 2 pode-se observar que a categoria $\mathrm{En}$ tretenimento foi a de maior frequência relativa, com P4 desempenhado-a em $15,8 \%$ das vezes observadas. Já a categoria Alimentação não teve nenhum registro para P2 e P3. Observa-se que P5 foi a mãe que mais desempenhou a categoria Interação Social - 14.3\% das observações foi nesta categoria.

Na figura 3 observa-se que em Amamentação o índice mais alto foi o de P3 com 30,3\% e o menor por P4 igual a $12,5 \%$. Na categoria Cuidado com o Bebê, 
P2 registrou um índice alto com $44,2 \%$ e P5 o mais baixo com $20,3 \%$. Em relação à categoria Carícias,

\section{9,7\% apresentada por P5 e a menor foi $4,2 \%$ por P1.}

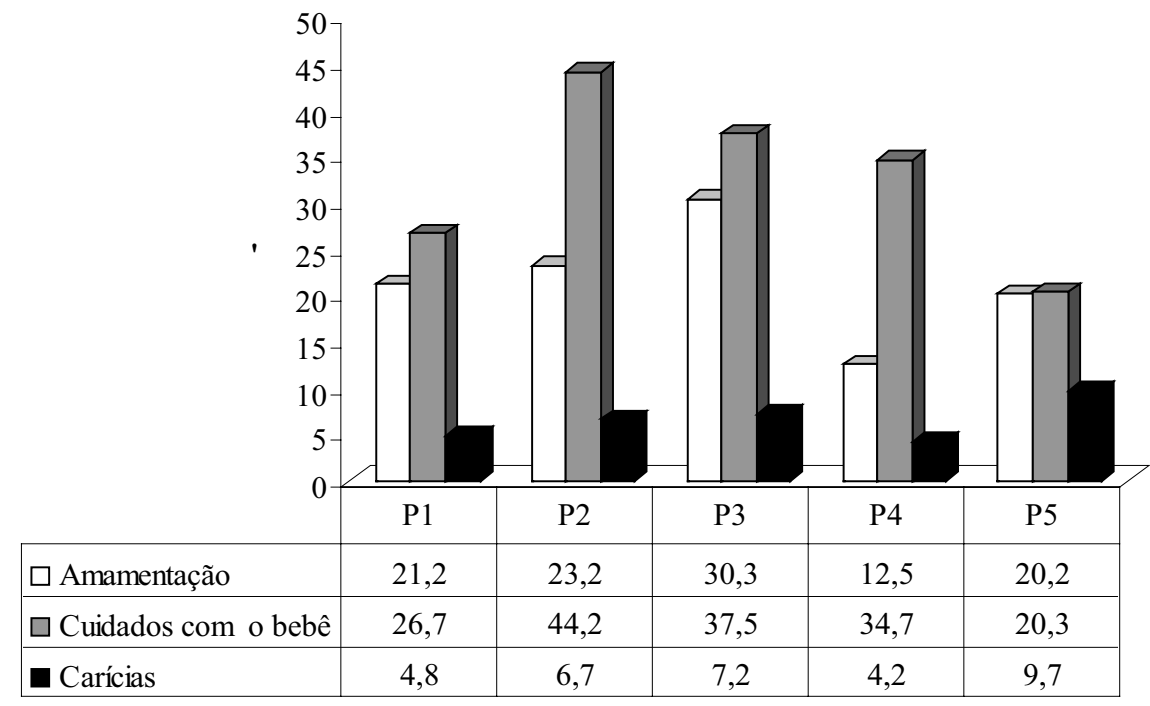

Figura 3. Frequências relativas dos resultados das observações das mães (cinco dias) referentes aos cuidados neonatais.

No que diz respeito às entrevistas, não foi encontrada qualquer resistência das participantes em falar sobre os contextos investigados - vida afetiva e sua vida com a família de origem - ao contrário, elas foram bastante participativas. Uma hipótese é de que na situação de internamento, as conversas se restringiam aos problemas relacionados ao bebê, de modo que a entrevista possibilitou momentos de reflexão sobre elas e suas vidas pessoais.

As categorias de registro mais frequentes foram as de Sofrimento e Apoio. A incidência de Sofrimento foi maior no contexto de Vida Afetiva e o de Apoio na Família de Origem, o que pode significar que as dificuldades afetivas encontradas podem estar sendo minimizadas pela rede de apoio familiar.

Uma das mães enfatizou o Contexto Vida Afetiva, podendo-se supor que ela passava por momentos difíceis em seu relacionamento, visto que Sofrimento teve alta incidência, corroborando com os índices obtidos no IDB. Em sua fala esta mãe também demonstrou encontrar Apoio na figura paterna, ao mesmo tempo, que demonstrou autoestima quando disse:

O meu pai acha que eu tenho muita responsabilidade. Ele acha muito bonito o jeito que eu cuido dos meus filhos. Eu acho que é por isso que ele me dá muita força, ele vê que eu me esforço. É só dizer o que tô precisando e ele (pai) me ajuda, se ele tiver $(P 1)$.
Já a fala de outra mãe registrou maior frequência quanto à Família de Origem, talvez por ser a mais nova (16 anos) e ainda depender emocionalmente de seus pais. Ela levava uma vida tranquila com o marido, porém permanecia muito ligada ao contexto de Família de Origem. Em relação ao Sofrimento, a mesma mãe registrou em algumas falas este sentimento em relação à Família de Origem, em virtude da morte de seu irmão. Esta variável teve grande influência no estado emocional da participante, que no IDB teve seu índice aumentado da primeira para a segunda aplicação. Pode-se inferir, também, que a participante devido a este motivo passou a não se alimentar adequadamente, podendo ter influenciado no retardamento de sua alta, em virtude do pouco ganho de peso do bebê.

Ainda para outra mãe, o contexto mais mencionado foi o de Vida Afetiva, onde declarou problemas com o namorado, o que fez com que a categoria Sofrimento fosse mais frequentemente citada. O Sofrimento, também foi registrado no contexto Lazer e Enfermaria Canguru. Outras categorias como Autopercepção, Autonomia e Alegria foram encontradas com menores frequências. As falas demonstraram um descontentamento com sua relação amorosa e sugeriram que a participante encontrava-se bastante chateada com os acontecimentos externos. Às vezes, procurava justificar o comportamento do namorado, talvez para ame- 
nizar sua decepção. No entanto, suas falas se apresentavam como se a participante estivesse muito confusa. Ela disse:

\begin{abstract}
Ai quando eu fiz uns sete meses e meio, foi quando eu tive problema e vim parar aqui. E até agora ele não veio... Ai eu voltei a vir pra cá e me internei aqui no canguru e até agora ele não veio. E eu não sei porque... Ele tem condições de vir e não veio, não sei por que, mas ele se mostra uma pessoa bem interessada, que quer, mas até agora... Aí eu fico pensando ,aqui a gente fica parada aqui, né? O tempo que a gente tem é pra pensar. Ai eu fico pensando assim: Não sei, eu sinceramente não quero mais, não por não gostar dele, porque eu ainda gosto. A gente faz uma balança a gente pesa os prós e os contra e eu acho que tem mais coisas contra do que a favor (P3).
\end{abstract}

Esta mãe demonstrou um pouco de estabilidade quando falou de sua relação com a família de origem e do apoio que encontrava na mesma:

A gente já conversa sobre tudo e ela (mãe) dá muita força. Graças a Deus, aquela distância que eu sentia antes que tinha, hoje em dia não existe mais... Qualquer coisa a minha melhor amiga é ela (mãe) (P3).

Para outra mãe o contexto mais citado foi o de Vida Afetiva, mas diferentemente de outras mães, ela mantinha uma relação estável e tranquila com seu companheiro. A mesma mãe demonstrou ter desejado a gravidez. A categoria de registro que obteve maior menção foi a de Alegria e em seguida Sofrimento, no entanto, em Sofrimento suas respostas referiram à sua saúde e à saúde do bebê.

Em relação ao contexto Enfermaria Canguru registrou-se uma incidência maior de categorias de registro Sofrimento. Quanto à Família de Origem, percebe-se a incidência de falas relativas às categorias de registro concernentes a Apoio e Sofrimento.

\section{DISCUSSÃO}

Os resultados obtidos através do Inventário de Depressão de Beck - IDB (Gorestein \& Andrade, 1998) demonstraram que três participantes na primeira aplicação (P1, P2, e P3) apresentaram índices que indicam sintomas depressivos, valores estes que podem estar relacionados ao que Tessier e cols. (1998) discutiram. Segundo estes autores, as mães precisam lidar com o estresse e os sentimentos de inadequação, além de ficarem afastadas de seus bebês em decorrência do nascimento prematuro e da longa estadia no hospital.
Por outro lado, Afonso, Wahlberg \& Persson (1989) sugeriram que "a Prática Mãe-Canguru teria uma influência positiva ajudando a mãe na superação mais rápida deste processo" (p. 56). Os dados obtidos no IDB corroboraram esta hipótese, pois houve uma queda nos índices de depressão da primeira para a segunda aplicação, na maioria das mães. A única mãe que obteve um índice mais alto na segunda aplicação do IDB (P2) relatou, na entrevista de história de vida, a morte de um irmão ao qual era muito ligada e que este fato havia causado um grande sofrimento principalmente por ter ocorrido durante sua estada no hospital. Esta variação detectada pelo instrumento demonstra a sensibilidade do mesmo para sintomas depressivos, conforme discutido por Gorestein (1998).

No que concerne ao Questionário de Aceitação Materna - QAM (Cattaneo e cols., 1998a) os resultados encontrados são semelhantes aos obtidos por Gadelha e cols. (2002), e apontaram $100 \%$ de satisfação com o Método. Já Cattaneo e cols. (1998a) não encontraram o mesmo grau de satisfação. Nesta pesquisa demonstrou-se que apesar da aceitação, algumas mães afirmaram preferir estar em casa.

Os resultados obtidos quanto à capacidade de cuidar do bebê em casa foram semelhantes aos obtidos por Gadelha e cols. (2002). Apenas uma mãe declarou sentir-se insegura para cuidar do mesmo, pois o bebê era muito pequeno; apesar de já ter criado três filhos, estava preocupada por que se acontecesse algo, eles moravam muito longe do hospital. Quanto à preocupação consigo mesmas, três das mães declararam estar preocupadas consigo, enquanto duas não estavam. Interessantemente, as mães que declararam estar preocupadas consigo, foram as que apresentaram maiores índices no IDB, tal resultado pode estar ligado a motivos externos ao Hospital, relativos a problemas familiares. Esta hipótese pôde ser fortalecida considerando os relatos obtidos nas entrevistas das mesmas, quando duas das mães relataram problemas relativos à vida afetiva, e uma delas, conforme relatado anteriormente, tinha sofrido a perda de um membro da família o que justificaria seu estado emocional.

No que tange à concordância dos familiares (marido e família de origem) sobre a participação da díade no programa, a aceitação foi positiva nas duas aplicações, com exceção de uma mãe que na primeira aplicação não respondeu, por não ter podido avisar previamente seus familiares de sua inclusão no programa. Os resultados aqui obtidos: $80 \%$ para o pai e $80 \%$ para a família diferiram dos de Gadelha e cols. (2002) que obteve concordância do pai de $67 \%$ e da família 
45,3\%. Porém, os resultados obtidos assemelham-se aos de Cattaneo e cols. (1998a), que registrou 84\% de concordância paterna e $83 \%$ de familiar. Deve-se levar em consideração que a variável Apoio Familiar é fundamental para a aceitação e bem estar materno no programa. Dentre as maiores preocupações apresentadas pelas mães deste estudo, assim como em Gadelha e cols. (2002), constavam a preocupação com os filhos que ficaram em casa, o ganho de peso e saúde do recém nascido e a situação financeira da família. As observações comportamentais foram realizadas com o objetivo de detectar padrões que indicassem desconforto no contexto físico e social de internamento, não detectável pelas verbalizações nas entrevistas ou nos instrumentos utilizados.

O primeiro cuidado ao analisar dados de observação dos comportamentos não verbais é integrá-los ao conjunto dos dados obtidos por outros instrumentos e analisá-los à luz deste conjunto. Tratando os resultados aqui obtidos desta perspectiva, os registros diários, permitiram uma visão geral das características dos comportamentos apresentados pelas mães durante a participação no programa, além das variações dos mesmos entre as participantes. As variações encontradas foram cuidadosamente analisadas com base em outros indicadores, uma vez que uma frequência menor ou maior em algum padrão comportamental podia ter significados diferentes. Um dado que pareceu significativo foi o desempenho de uma mãe na categoria Entretenimento com $15,8 \%$, porcentagem aparentemente alta que poderia ser interpretada como desleixo com outras atividades, o que não necessariamente era verdade, visto que ela foi ao mesmo tempo observada com o bebê no Canguru e amamentando.

Na categoria Cuidados com o Bebê a necessidade de cuidados específicos ficou ainda mais evidente. Esta foi a categoria que obteve maior frequência de registro, e este é o resultado esperado uma vez que a maioria desses comportamentos são cuidados que devem ser seguidos como premissa do Método MãeCanguru (ficar com bebê no canguru). Tais resultados nos levam a concluir que, a maioria das participantes desempenhou corretamente as atividades do MMC, corroborando com os resultados obtidos no QAM. Outro dado interessante, nesta categoria, foi que as frequências mais altas foram desempenhadas pelas mães primíparas. $\mathrm{O}$ fato de ser o primeiro filho pareceu demandar maior atenção e cuidados, talvez em decorrência da inexperiência. As outras duas mães multíparas, apesar de apresentarem uma frequência alta de cuidados, o fizeram menos quando comparadas às primíparas. Este dado parece fortalecer a hipótese da experiência/inexperiência, com estas últimas aparentando mais segurança e conhecimento dos cuidados necessários.

Analisando-se o tempo de permanência no programa esperava-se que aquelas mães que obtivessem os maiores índices de desempenho de Cuidado com o Bebê também apresentassem um tempo de permanência menor no programa. Os dados obtidos não confirmaram esta expectativa, uma vez que as mães primíparas permaneceram mais tempo no programa. As multíparas tiveram alta precoce, fortalecendo a ideia de que a experiência pode ser uma variável que se traduza em qualidade dos cuidados. Este dado é importante por indicar para as equipes de acompanhamento de programas Mãe-Canguru, a necessidade de maior atenção com as mães primíparas.

Além das atividades preconizadas pelo Método Canguru, uma outra explicação para a alta frequência da categoria Cuidados com o Bebê pode ser baseada nas propostas de Feldman, Eidelman, Sirota e Weller (2002) e Matthresen, Ransjo-Arvidson, Nissen e Uvmas-Moberg (2001) que concluíram que o contato pele a pele estimula a liberação de oxitocina o que influencia diretamente as respostas maternas, afetando seu humor e favorecendo o contato com o bebê, além de ajudar na diminuição de sintomas depressivos.

Quanto à categoria Carícias, todas as participantes apresentaram uma baixa frequência de desempenho, se comparada às outras duas relacionadas ao bebê. Isto pode ser justificado devido à bolsa Canguru ser um obstáculo às carícias. Apesar do contato pele a pele intensificar a ligação entre mãe-bebê como afirma Tessier e cols. (1998), a posição e o tempo que os bebês passam na bolsa dificultam o desempenho de muitas carícias. Aparentemente, existe uma tendência maior na ocorrência destas carícias em momentos distintos: durante a amamentação (como também registrado por Oliveira, 1996) e quando há a retirada do bebê da bolsa canguru.

Em Amamentação a variação de frequências está relacionada à forma com que os bebês eram amamentados. Por exemplo, a mãe que obteve maior frequência nesta categoria alimentou o bebê por sonda. Nesta técnica de alimentação gastava menos tempo e demandava menor atenção ao bebê, uma vez que é necessário apenas segurar o recipiente com leite em uma altura adequada. Esta tarefa possibilitava o desempenho de outras atividades concomitantemente, como o Entretenimento, cuja frequência na referida mãe foi 
bastante alta $(15,8 \%)$ e Observações do Ambiente, uma vez que a mãe não precisava ficar olhando o tempo todo para o bebê. A variação de frequência na categoria Amamentação induzida pela forma do aleitamento ficou mais evidente quando se analisou o desempenho da participante que obteve o maior índice de registro nesta categoria. Uma das mães participantes (primípara) foi observada amamentando $30,3 \%$ das vezes em que seu comportamento foi registrado. Duas condições podem ser consideradas para explicar esta alta frequência: a primeira é que a amamentação acontecia ao seio, o que demandava mais tempo de permanência executando o comportamento, pois este dependia do desempenho do bebê e a segunda era a grande dificuldade que ela apresentava para amamentar. Esta dificuldade gerava a necessidade de complementação do aleitamento por copinho. Claramente se demonstra que nem sempre a maior frequência de um desempenho se traduz em eficiência. As demais participantes apresentaram frequências semelhantes (em torno de $20 \%$ ), e todas amamentaram somente ao seio, sendo que duas das mães que assim amamentaram (multíparas) receberam alta precocemente, fortalecendo a ideia de que a experiência/habilidade em amamentar é variável importante.

Outra categoria que chamou atenção por sua baixa frequência foi Alimentação. Isto pode ser explicado pelo horário das observações serem após o almoço das mães e/ou por elas estarem desempenhando atividades relativas ao Método.

As frequências relativas aos comportamentos das mães voltados para elas mesmas foram baixas, mas isto pode ter ocorrido em virtude de estarem a maior parte do tempo cuidando do bebê. Em Interação Social e Entretenimento, ver televisão foi o comportamento registrado com maior frequência, pois mesmo estando cuidando do bebê ou amamentando-o não havia impedimento para a sua realização. A mãe que registrou maior índice de interação social, por ser multípara, poderia ter tentado ajudar as outras mães nos cuidados com o bebê. Outras duas mães, primíparas, poderiam ter ido buscar informações sobre os cuidados.

Os cuidados pessoais e corporais das mães foram pouco desempenhados, talvez em virtude da rotina do programa. Observou-se que pouco antes do horário de visitas as mães procuravam cuidar-se e arrumar-se para receber seus visitantes.

O conjunto de variáveis, discutidas aqui, para a categoria Cuidado com o Bebê, indicam a necessidade de uma compreensão mais monista e integrada das respostas maternas em programas Mãe-Canguru. Os dados deste trabalho apontam para a necessidade de um acompanhamento mais intenso das condições de humor e satisfação das mães participantes.

Além dos dados já discutidos até aqui, as análise das falas das participantes nas entrevistas esclareceu aspectos ainda obscuros nos dados. O trabalho de análise e interpretação das categorias verbais para cada participante nos permitiu compreender que apesar de cada uma dar ênfase a problemas de vida diferentes, esta técnica de coleta de informações é muito esclarecedora, uma vez que contextualiza os dados para além do momento e situação observadas, conferindo à pesquisa profundidade na compreensão da problemática estudada.

Nas entrevistas, o contexto mais citado foi o de Vida Afetiva, ou seja, os acontecimentos de vida afetiva são os que pareceram exercer maior influência no subjetivo das participantes, principalmente os relacionados a Sofrimento. Quanto ao contexto Família de Origem o registro mais frequente das falas das participantes foi relativo ao Apoio. Isto nos leva a inferir que as participantes vêem na família um ponto de refúgio e apoio, com o qual podem contar em situações extremas.

Percebe-se que o que foi relatado nas entrevistas exerce forte influência nas participantes, uma vez que as mesmas não conseguiram desligar-se de problemas externos, ainda mais somando o estresse do nascimento do bebê prematuro. Nota-se que as entrevistas pareceram uma forma de desabafo, principalmente das participantes que passavam por problemas pessoais de ordem afetiva.

\section{CONSIDERAÇÕES FINAIS}

Os instrumentos utilizados nessa pesquisa mostraram-se sensíveis e adequados para o estudo das questões formuladas. Através deles pudemos detectar como essas mulheres se sentiram e como perceberam sua participação no Programa Mãe-Canguru.

Tessier e cols. (1998), Cattaneo e cols. (1998a), Charpak e cols. (1997) e Lundigton-Hoe e cols. (2000) entre outros, demonstraram que o Programa Mãe-Canguru é benéfico para os bebês prematuros e de baixo peso, favorece o vínculo entre mãe-bebê, e reduz os custos hospitalares. Entretanto, o sucesso do programa depende, fundamentalmente, da vontade da mãe em participar, do apoio familiar e de uma equipe de profissionais compreensiva e bem preparada. Visto que essas mulheres precisam tomar uma decisão im- 
portante, em detrimento de outros fatores que também são significativos para elas como: filhos, marido, trabalho, etc., muitas vezes a estadia prolongada no hospital pode se tornar difícil. No entanto, constatamos que houve um grau razoável de tolerância ao Programa Mãe-Canguru entre as participantes.

Apesar dos problemas relatados, desempenharam, regularmente, o Método. Porém, às vezes, com algumas alterações como: não colocando o bebê na bolsa, ficando apenas com ele no colo. Este tipo de atitude causava leves atritos entre a participante e a equipe hospitalar. Com relação ao manejo do programa, este deve reavaliar a forma com que as mães tomam conhecimento de sua participação porque, por vezes, as mães não têm conhecimento prévio e quando chegam para visitar o bebê na Terapia Intensiva, são informadas que irão direto para o Canguru. Neste momento, elas recebem uma pequena informação sobre o Método, suas vantagens e benefícios para o bebê e iniciam sua participação. Essas mulheres pareceram não ter muitas opções e acabavam por participar do programa.

Um ponto importante, que também deve ser levado em consideração é o pouco contato que as mães têm com seus familiares - uma hora diária, durante a qual só uma pessoa pode entrar para visitar. Uma sugestão é que este período poderia ser estendido e a participação de outros membros da família no Método Canguru deveria ser incentivada, ajudando assim, a mãe a carregar sua árdua tarefa (Ades, 2001; Hrdy, 2001), uma vez que o programa se baseia e fixa suas bases na organização da familiar nuclear, na valorização do amor materno e na compreensão do papel de mãe, que induz as participantes a obrigações impostas pela sociedade.

De forma geral, o tempo de permanência na Enfermaria Canguru é utilizado pelas participantes como um momento reflexivo sobre suas vidas e seus problemas. Tal fator merece destaque, pois pode influenciar no cuidado desempenhado no Método.

Curiosamente, o Método Mãe-Canguru, no Brasil, é oferecido apenas em hospitais que atendem pacientes do SUS, onde encontramos, geralmente, pessoas com nível de escolaridade baixo, e sem muita opção de escolha, o que talvez torne a aceitação mais fácil. $\mathrm{Na}$ literatura pesquisada, não foi encontrada referência à oferta do programa em hospitais que recebem uma população de classe média/alta e nem o mesmo é oferecido por planos de saúde. Isto levanta uma questão que necessita ser investigada. Quais as variáveis implicadas nesta ausência de oferta já que há tantos benefícios bem estabelecidos para a recuperação do bebê? Isto nos leva a perguntar se outras mulheres teriam alguma resistência em participar de um programa como esse. Se for isto, quais as variáveis envolvidas? Atualmente, as realizações pessoais de uma mulher não estão estritamente ligadas à maternidade, ainda que este sentimento constitua um dos pilares da identidade feminina.

Uma sugestão para que a estadia no programa se torne mais agradável é a realização de atividades diferenciadas da rotina do alojamento, como palestras, filmes e outras atividades educativas, que pudessem esclarecer as mães quanto aos benefícios e resultados do programa, orientar sobre cuidados nutricionais e de higiene com bebês prematuros após a alta, a prevenção de doenças sexualmente transmissíveis e planejamento familiar. Estudos como este ainda precisam ser desenvolvidos para que o programa possa ser aprimorado e possa propiciar às participantes momentos mais agradáveis, assim como melhores condições de estadia.

\section{REFERÊNCIAS}

Ades, C. (2001, maio). Instinto, não. Investimento. Superinteressante [entrevista concedida a M. F. Vomero]. Retirado em 16 de abril de 2003, de http://super.abril.com.br/superarquivo/ 2001/conteudo_180278.shtml.

Afonso, D. D., Wahlberg, V., \& Persson, B. (1989). Exploration of mother's reactions to the Kangaroo Method of prematurity care. Neonatal Network, 7, 43-57.

Brasil (1998). Ministério da Saúde. A mortalidade perinatal e neonatal no Brasil. Brasília: Fundação Nacional da Saúde/Ministério da Saúde.

Calil, H. M., \& Pires, M. L. N. (1998). Aspectos gerais das escalas de avaliação de depressão. Revista de Psiquiatria Clínica, 25(5), 240-244.

Carvalho M. R. (2001). Mãe Canguru: Prematuros no Brasil usufruem deste cuidado. Retirado em 22 de abril de 2003 de http://aleitamento.med.br/normacanguru.htm.

Cattaneo, A., Davanzo, R., Worku, B., Sujorno, A., Echeverria, M., Bedri, A., e cols. (1998a). Kangaroo Mother Care for low birthweight infants: A randomized controlled trial in different settings. Acta Paediatrica, 87(9), 976-985.

Cattaneo, A., Davanzo R., Uxa F., \& Tamburlini, G. (1998b). Recommendations for the implementation of Kangaroo Mother Care for low birthweight infants. Acta Paediatrica, 87, 440445.

Charpak N., Ruiz-Peláez, J., Figueroa, Z., \& Charpak, Y. (1997). Kangaroo Mother versus traditional care for newborn infants $<2000$ grams: A randomized, controlled trial. Pediatrics, 100(4), 682-688.

Feldman, R., Eidelman, A. I., Sirota, L., \& Weller, A. (2002). Comparison of skin-to-skin (kangaroo) and traditional care: Parenting outcomes and preterm infants development. Pediatrics, 110, 16-26. 
Fisher, H. (1995). Anatomia do amor: A história natural da monogamia, do adultério e do divórcio. Rio de Janeiro: Eureka.

Gadelha, C. M., Medeiros Filho, J. G., Mendes, G. A. C., Saad, S., \& Barbosa, I. (2002). Avaliação do Método Mãe-Canguru: Tempo de internação hospitalar, aceitação materna, laços psico-afetivos e intercorrências. Em M. F. W. Sousa (Org.), Iniciados: Vol. 8. (9a ed) (pp. 238-247). João Pessoa: Editora Universitária/UFPB.

Gorestein, C., \& Andrade, L. (1998). Inventário de Depressão de Beck: Propriedades psicométricas da versão em português. Revista de Psiquiatria Clínica, 25(5), 245-250.

Hrdy, S. B. (2001). Mãe natureza: Uma visão feminina da evolução. Maternidade, filhos e seleção natural. Rio de Janeiro: Campus.

Kambarami, R. A, Chidede, O., \& Pereira, N. (2003). Long term outcome of preterm infants discharged home on kangaroo care in a developing country. Annuals of Tropical Paediatric,. 23, 55-59.

Lundigton-Hoe, S., Nhuha, N., Swinth, J., \& Satyshur, R. (2000). Kangaroo Care compared to incubators in maintaining body warmth in preterm infants. Biological Research for Nursing, 2(1), 60-73.

Matthresen, A. S., Ransjo-Arvidson, A. B., Nissen, E., \& UvnasMoberg, K. (2001). Postpartum maternal oxytocin release by newborn effects of infant hand massage and sucking. Birth, 28, 20-21.

Miltersteiner, A., Miltersteiner, D., Rech, V, \& Mole, L. (2003). Respostas fisiológicas da posição canguru em bebês pré- termos, de baixo peso e ventilado espontaneamente. Saúde Materno Infantil, 3(4), 447-455.

Moura, S. S. R. (2003). Maternidade e práticas de saúde: O instituído e o possível. Dissertação de mestrado não-publicada, Universidade Estadual Paulista, Assis.

Oliveira, N. G. (1996). Amamentação em creche no local de trabalho. Dissertação de mestrado não-publicada, Universidade de São Paulo.

Queiroz, M. I. P. (1988). Relatos orais: Do "indizível” ao "dizível”. Em O. R. M. Simson, (Org.), Experimentos com história de vida (pp. 14-43). São Paulo: Vértice.

Ribas, A. F. P., \& Moura, M. L. S. (2004). Responsividade materna e teoria do apego: Uma discussão crítica do papel de estudos transculturais. Psicologia: Reflexão e Crítica, 17(3), 315-322.

Tessier, R., Cristo, M., Velez, S., Girón, M., Figueroa de Calume, Z., Ruiz-Pelaez, J., Charpak, Y., \& Charpak, N. (1998). Kangaroo Mother care and the bonding hypothesis. Pediatrics, 102(2), 390-391.

Tokumaru, S. (2001, maio). Instinto, não. Investimento. Superinteressante [entrevista concedida a M. F. Vomero]. Retirado em 16 de abril de 2003, de http://super.abril.com.br/superarquivo/ 2001/conteudo_180278.shtml.

Xavier, C. C. (2000). O Método Cuidado Mãe Canguru. Retirado em 28 de março de 2003, de http://medicina.ufmg.br/edump/ ped/canguru.htm.

\section{APÊNDICE A}

\section{QUESTIONÁRIO DE ACEITAÇÃO MATERNA EM RELAÇÃO AO MÉTODO MÃE-CANGURU}

Satisfeita (feliz) com a prescrição do método?

Preferia o outro?

Acha o método fácil?

Considera o método conveniente?
Sente-se confortável?

Sente-se preocupada com o bebê?

Sente-se preocupada consigo?

Ajuda as outras mães?

O pai concorda com o método?
Recebido: 22/01/2007

Última revisão: 03/09/2008 Aceite final: 10/10/2008

Sobre as autoras:

Manuela Beltrão Oliveira e Silva: Mestre em Teoria e Pesquisa do Comportamento (Universidade Federal do Pará).

Regina Célia Souza Brito: Doutora em Psicologia (Universidade Federal do Pará).

Endereço para correspondência: Programa de Pós-graduação em Teoria e Pesquisa do Comportamento - Centro de Filosofia e Ciências Humanas - Universidade Federal do Pará - Campus Universitário do Guamá - 66075-110 Belém - PA - Endereço eletrônico: silvamanu@interconect.com.br. 